\title{
Simulations of the neutral structure within the dusk side aurora
}

\author{
H. F. Parish and L. R. Lyons \\ Department of Atmospheric and Oceanic Sciences, University of California Los Angeles, 405, Hilgard Avenue, Los Angeles, \\ CA 90095-1565, USA
}

Received: 28 April 2006 - Accepted: 1 September 2006 - Published: 20 October 2006

\begin{abstract}
Observations of neutral winds from rocket release experiments within the premidnight and postmidnight substorm recovery phase aurora, show very large E-region neutral winds of several hundred $\mathrm{m} / \mathrm{s}$, where winds measured on the dusk side are even larger than those on the dawn side. These large winds are also associated with strong shears, and there is evidence that some of the regions below these shears may be unstable. The mechanisms which generate this strong vertical structure are not well understood. It is also not known whether the acceleration conditions in the pre and post midnight sectors of the aurora may produce significantly different neutral responses on the dawn and dusk sides. Simulations have been performed using a three-dimensional high resolution limited area thermosphere model to try to understand the neutral structure within the dawn and dusk side aurora. When simulations are performed using auroral forcing alone, for equivalent conditions within the dawn and dusk sectors, differences are found in the simulated response on each side. When measured values of auroral forcing parameters, and background winds and tides consistent with recent observations, are used as model inputs, some of the main features of the zonal and meridional wind observations are reproduced in the simulations, but the magnitude of the peak zonal wind around $140 \mathrm{~km}$ tends to be too small and the maximum meridional wind around $130 \mathrm{~km}$ is overestimated. The winds above $120 \mathrm{~km}$ altitude are found to be sensitive to changes in electric fields and ion densities, as was the case for the dawn side, but the effects of background winds and tides on the magnitudes of the winds above $120 \mathrm{~km}$ are found to be relatively small on the dusk side. The structure below $120 \mathrm{~km}$ appears to be related mainly to background winds and tides rather than auroral forcing, as was found in earlier studies on the dawn side, although the peak magnitudes of simulated wind variations in the 100 to $120 \mathrm{~km}$ altitude
\end{abstract}

Correspondence to: H. F. Parish

(helen@atmos.ucla.edu) range are smaller than those observed. The source of the strong shears measured around $110 \mathrm{~km}$ altitude on the dusk side is uncertain, but may be related to different kinds of oscillations, such as gravity waves, non migrating semidiurnal tides, or secondary oscillations produced by non linear interactions between waves.

Keywords. Atmospheric composition and structure (Airglow and aurora) - Meteorology and atmospheric dynamics (Thermospheric dynamics; Waves and tides)

\section{Introduction}

Rocket, incoherent scatter radar, and satellite measurements made within the premidnight substorm recovery phase aurora at Poker Flat, Alaska (65 N, $147 \mathrm{~W}$ geographic), during February and March 1978 (Mikkelsen et al., 1981), show strong E-region neutral winds of over $350 \mathrm{~m} / \mathrm{s}$, with large associated wind shears. Strong winds and wind shears were also observed within the postmidnight recovery phase aurora, during the coordinated ARIA (Atmospheric Response in Aurora) campaigns (Larsen et al., 1995, 1997; Anderson et al., 1995) and during some pre-ARIA observing campaigns (Larsen et al., 1989). The generation of E-region winds of the observed magnitudes on the dawn or the dusk side is not easily explained by auroral processes alone, and the mechanisms which produce the observed strong vertical structure are not well understood. The effects of the observed strong winds and shears on dissipation processes and on the general circulation in the thermosphere are not well known. Enhanced ion densities and electric fields at high latitudes associated with the aurora may have effects at lower latitudes, as well as in the auroral zone, possibly causing composition changes (Parish et al., 1994), and generating gravity waves which propagate to lower and higher latitudes (Parish et al., 1997; Walterscheid and Lyons, 1989; Richmond and Matsushita,

Published by Copernicus GmbH on behalf of the European Geosciences Union. 
1975). Observations (Larsen et al., 1997) and simulations (Parish et al., 2003), suggest that the shears below the wind maxima in the postmidnight sector may sometimes unstable, with Richardson number less than 0.25 , which could cause enhanced eddy diffusion, generate waves, or cause large localized composition changes (Christensen et al., 1997).

The winds on the premidnight side are found to be as large or even larger than those on the postmidnight side. The largest winds observed on the dawn side during the ARIA campaigns were around $220 \mathrm{~m} / \mathrm{s}$, occurring during the ARIA II campaign, for an interval of average Kp between 4 and 5 (Larsen et al., 1997). The peak wind velocites for the different dawn side campaigns are found to show some dependence on geomagnetic activity level. However, the premidnight measurements of Mikkelsen et al. (1981), obtained during an interval with $\mathrm{Kp}$ between 3.5 and 5.5, show maximum wind velocities around 350 to $400 \mathrm{~m} / \mathrm{s}$, which are almost twice as large as the maximum winds seen on the postmidnight side. The maximum velocities on the dusk side occur at around 130 to $140 \mathrm{~km}$ altitude, which is higher in altitude than the largest peaks observed on the dawn side, which occur around 110 to $120 \mathrm{~km}$ altitude, although smaller maxima of around 100 to $150 \mathrm{~m} / \mathrm{s}$, and associated shears, are seen on the dusk side around $110 \mathrm{~km}$ altitude. On the dawn side, the winds around 130 to $140 \mathrm{~km}$ altitude are generally very small, with the exception of the ARIA II measurements, where winds of around $200 \mathrm{~m} / \mathrm{s}$ are seen between 130 and $140 \mathrm{~km}$ altitude, above the main wind maximum. The available measurements therefore suggest that the wind structure on the dusk side may have significantly different characteristics from those on the dawn side.

It is unknown whether larger winds are consistently produced in the premidnight rather than the postmidnight sector. The conditions for accelerating winds on the dusk side may be different from those on the dawn side. On the dawn side Coriolis coupling of the zonal wind, and curvature acceleration, tend to act in the same direction, enhancing equatorwards flow across the aurora, but on the dusk side Coriolis tends to direct the flow towards the polar cap, opposing the effects of curvature, and reducing cross auroral flow. Also, changes in the interplanetary magnetic field (IMF) direction may affect the orientation of the high latitude convection relative to the background wind field differently in the dusk and dawn sectors (Parish et al., 2006; Weimer, 2001, 1996, 1995), and since the flow in the auroral oval is sensitive to the magnitude of the cross arc winds (see e.g. Parish et al., 2003, 2006; Walterscheid and Lyons, 1989; FullerRowell, 1985), changes in IMF may reduce or enhance flow on the dusk side, compared with the dawn side. There are currently very few observations of E-region neutral winds within the premidnight aurora, especially with the high vertical resolution given by rocket release experiments, which are able to show the presence of structures with small vertical scale sizes. Small scale phenomena have been found to be very important, e.g. the effects of large scale averages of parameters can be quite different from the combined effects of smaller individual peaks in the same parameters (FullerRowell, 1984), so it is important to try to understand the dusk side observations that are available.

Previous two-dimensional (2-D) high resolution models have been used to simulate small scale phenomema and neutral winds in the auroral zone (Fuller-Rowell, 1984; St. Maurice and Schunk, 1981; Richmond and Matsushita, 1975). Some 2-D simulations suggested that very large and even supersonic winds could be generated in the auroral zone under certain circumstances (Walterscheid et al., 1985; FullerRowell, 1985; Lyons and Walterscheid, 1985; Walterscheid and Lyons, 1989). However, 2-D latitude versus height models may not represent zonally varying phenomena well. More recent 2-D simulations of the dawn sector diffuse aurora used measured auroral parameters from the ARIA I campaign as model inputs, and compared the resulting simulated winds with observed winds from the same campaign (Brinkman et al., 1995). Whilst there was some agreement with the observations, the strong wind structure and wind magnitudes were not well reproduced. Simulations of the winds produced during the ARIA I campaign using a spectral general circulation model (Larsen et al., 1995), generated the characteristics of the observations above $140 \mathrm{~km}$, but the strength of the vertical structure in the E-region was not well reproduced. Simulations of winds generated within the dusk side aurora during the campaign of 28 February 1978, using the same spectral model (Mikkelsen and Larsen, 1993) reproduced some of the main features of the observations, although the simulated wind vectors were rotated relative to the observations, and Eregion maxima were too high in altitude. They suggested that the neutral response may be sensitive to the detailed longer term time history of Lorentz forcing and Joule heating.

More recent simulations of the dawn side diffuse aurora due to Parish et al. (2003) using a three-dimensional (3-D) high resolution model, with aurora input parameters based on values measured during the ARIA I campaign, achieved much closer agreement with the observed wind structures than obtained by Brinkman et al. (1995). Parish et al. (2003) suggested that propagating tides in the background wind field may be important in generating the observed vertical wind structures in the auroral zone. The results of Parish et al. (2003) also suggested that higher order tidal modes, such as the $(2,5)$ and $(2,6)$ modes (which have relatively short vertical wavelengths) may be the most important for generating the small vertical scale size structures found in the observations. Measurements from several ARIA campaigns, which were made during periods with differing levels of geomagnetic activity, suggest that there is a correlation between the geomagnetic activity level and the magnitude of the wind peaks and shears. However, the results of Parish et al. (2003, 2006) suggest that the observations are not well explained using auroral forcing processes alone, and that a combination of tidal and auroral forcing produces better agreement with the observations. In the simulations, the main features of the 
wind structure were generated, although the great strengths of the shears between 110 and $120 \mathrm{~km}$ altitude were not well reproduced.

In this study, dawn versus dusk differences in the neutral response are examined, and measurements from the dusk side campaign are analysed to give values for electric fields and ion densities over the period of the observations. The sensitivity of the neutral response to changes in the electric field and ion density, as well as changes in tidal forcing parameters in the background winds, has been determined, and the relative importance of different forcing mechanisms has been examined.

\section{The model}

The simulations described here were performed using a three-dimensional, high resolution, limited area, composition dependent, non hydrostatic model, described in Parish et al. (2003). The neutral response to auroral forcing is dependent on the ion drag terms in the momentum equations and the Joule heating terms in the energy equation, and the auroral forcing is adjusted by modifying the structure and magnitude of the simulated electric field and ion density. The simulated electric field is directed equatorward in the dawn sector, and poleward in the dusk sector, is assumed to have a Gaussian horizontal structure, and is assumed to be constant as a function of height. The background ion density is based on the Chiu (1975) empirical model (where the Chiu model is used rather than newer models for simplicity, as the background ion densities are generally small relative to the density enhancements in the E-region).

In the initial runs described here, which do not use specific observational inputs for the auroral forcing parameters, an enhancement to the background ion density is introduced, which is based on the electron density profile given by Walterscheid and Lyons (1989), using the hard energy spectrum of Lyons and Fennell (1986), with a maximum value around $8 \times 10^{11} \mathrm{~m}^{-3}$ at $110 \mathrm{~km}$ altitude. The horizontal structure of the ion density enhancement is assumed to have a Gaussian distribution. The magnetic field is directed downward with a constant value of $5 \times 10^{-5} \mathrm{~T}$. The model domain is centered at 65 degrees magnetic latitude, and the cross auroral direction is taken to lie along a magnetic meridian. The extent of the computational domain and aurora can be varied, and in these simulations the domain is specified as a region with vertical extent between $86 \mathrm{~km}$ and $451 \mathrm{~km}$ altitude, and horizontal dimensions $7140 \mathrm{~km}$ east-west and $3150 \mathrm{~km}$ north-south. The aurora itself has dimensions $3400 \mathrm{~km}$ east-west and $300 \mathrm{~km}$ north-south, centered at 65 degrees north. Auroral forcing is introduced gradually over a time interval of $5 \mathrm{~min}$ and maintained for simulation times of 1 to $3 \mathrm{~h}$. Global background winds are given by the 3-D CTIP (Coupled Thermosphere Ionosphere Plasmasphere) model (Bailey et al., 1997; FullerRowell et al., 1987). The CTIP model includes different propagating diurnal and semidiurnal tides, assumed to propagate up from the troposphere and stratosphere. Large scale winds from the CTIP model are rotated into magnetic coordinates and interpolated onto all the grid points of the high resolution model, to give the background winds and tides in the region of the aurora.

\section{Simulations with auroral forcing only}

Model runs were performed for equivalent conditions in the premidnight and postmidnight sectors of the aurora to determine any differences in the neutral response. The same ion density enhancement was applied on the dawn and dusk sides, with maximum $8 \times 10^{11} \mathrm{~m}^{-3}$ at $105 \mathrm{~km}$ altitude, where the background ionosphere was provided by the Chiu model. The electric field maximum was $50 \mathrm{mV} / \mathrm{m}$, equatorward on the dawn side, poleward on the dusk side. The simulations were run for 2 simulated hours. In these examples auroral forcing only was applied, with no background winds.

Figure 1 shows contours of the eastwards and northwards winds versus south-north distance and height, produced by dawn and dusk side simulations, plotted at the center of the longitudinal domain. There are large westwards winds on the dusk side and large eastwards winds on the dawn side, consistent with the opposite direction of the electric field on each side, which affects the direction of the ion convection and the ion drag driven neutral winds. Zonal wind magnitudes show a single peak around $170 \mathrm{~m} / \mathrm{s}$ at $140 \mathrm{~km}$ altitude on the dusk side, and a peak around the same magnitude at $120 \mathrm{~km}$ on the dawn side, with slightly larger winds at higher altitudes on the dawn side. The meridional winds show large northwards and southwards magnitudes, of 150 to $200 \mathrm{~m} / \mathrm{s}$, in opposite directions on the dawn and dusk sides. The wind pattern converges into a smaller latitudinal cross section in the dusk sector, due to reduced cross auroral flow on the dusk side compared with the dawn side, as discussed above.

Figure 2 shows profiles of the eastwards and northwards winds versus height for the same simulations, plotted at the center of the latitudinal and longitudinal domains. Strong zonal wind velocities are produced on both the dawn and dusk sides, in opposite directions. The maximum meridional wind is larger on the dusk side and the altitude of the peak in the zonal and meridional winds is higher in altitude on the dusk side. The shear under the peak is stronger on the dawn side than the dusk side. The Richardson number of the region under the peak is greater than 0.25 on the dusk side, suggesting that the atmosphere is not unstable, whereas the region under the peak on the dawn side may be unstable, with Richardson number $<0.25$. The zonal winds on the dusk side around 130 to $140 \mathrm{~km}$ altitude do not, however, appear to be larger than those on the dawn side for equivalent auroral forcing conditions. 
(a)

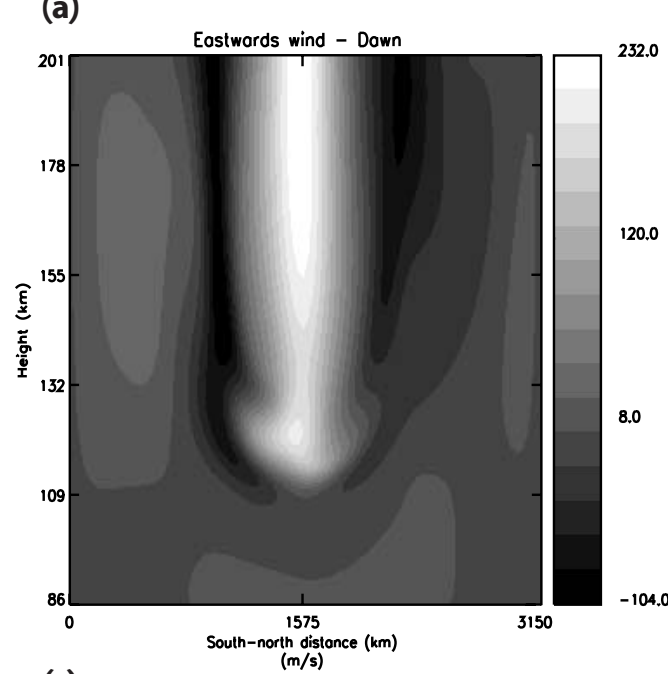

(c)

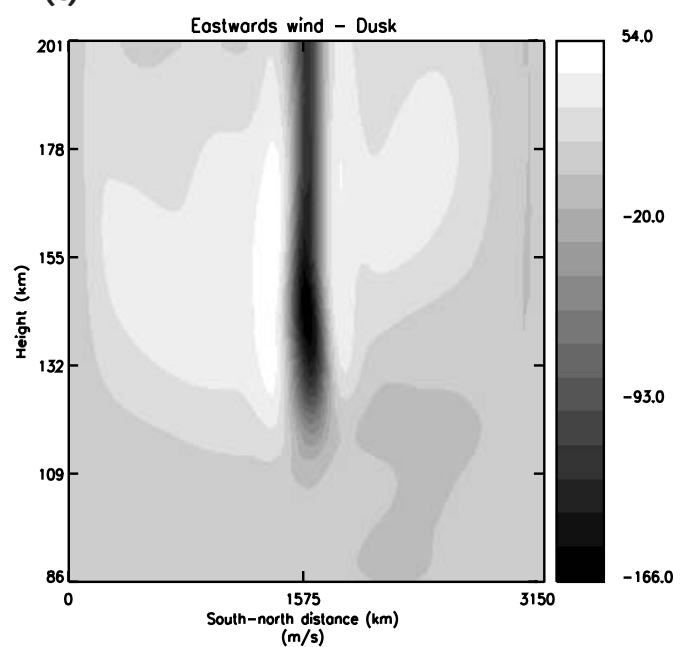

(b)

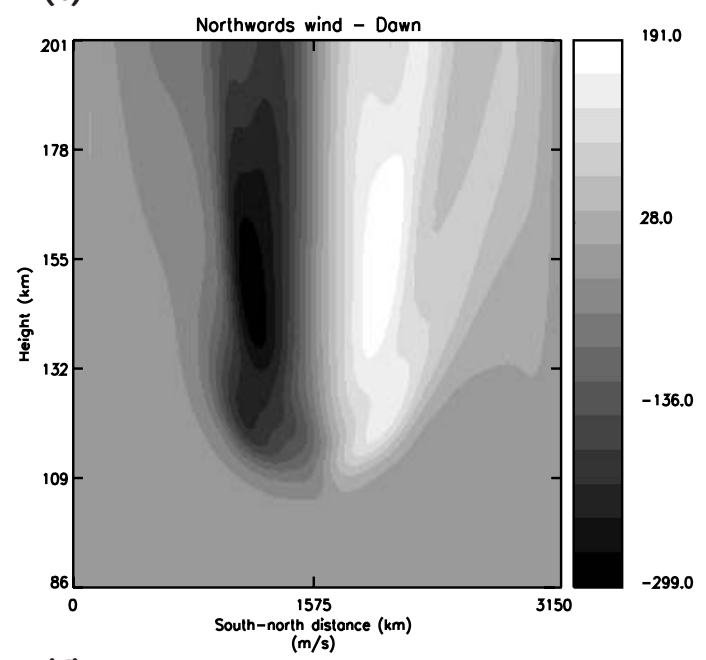

(d)

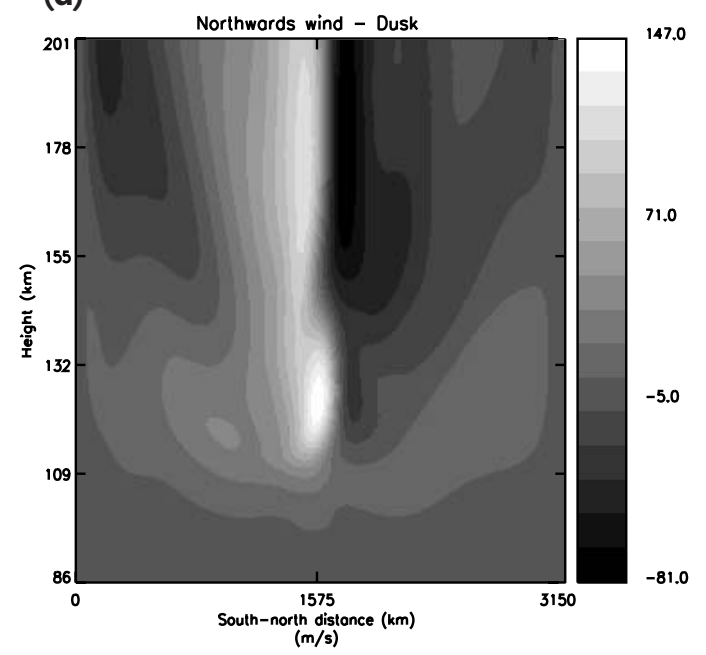

Fig. 1. Contours of simulated neutral winds versus south-north distance and height, plotted at the center of the longitudinal domain, for equivalent conditions on the dawn and dusk sides.

\section{Comparison with observations}

Measurements of ion densities and electric fields from the dusk campaign of 28 February 1978 were used to provide auroral forcing parameters for the model simulations, so that the results of the model simulations could be compared with the observations of the meridional and zonal winds made during the same campaign, in order to determine the processes which generate the observed neutral wind response.

\subsection{Dusk side masurements}

Simultaneous rocket, ground based and satellite measurements, were made within the premidnight recovery phase aurora, at Poker Flat, Alaska (65.1 N, 212.5 E geographic), during February and March 1978 (Mikkelsen et al., 1981). The measurements made on 28 February 1978, show winds of
350 to $400 \mathrm{~m} / \mathrm{s}$ around $130 \mathrm{~km}$ altitude and strong shears (see Fig. 1 of Mikkelsen et al., 1981). Wind profiles with similar structures and large magnitudes were also seen two days later on 2 March 1978 (Mikkelsen et al., 1981). The winds on both days are even larger than those observed within the postmidnight aurora during the ARIA campaigns (Larsen et al., 1995, 1997), and may represent conditions which occur regularly with the region of the dusk side aurora. It is not known whether even larger winds may be consistently produced in the premidnight rather than the postmidnight sides of the aurora, but the results of simulations shown in Fig. 2 suggest that auroral forcing alone, of the same magnitude on the dawn and dusk sides, does not generate larger winds on the dusk side.

Observations during the campaign on 28 February 1978 were made during and in the recovery phase of a substorm which took place between 02:40 to 03:30 UT. A rocket was 
(a)

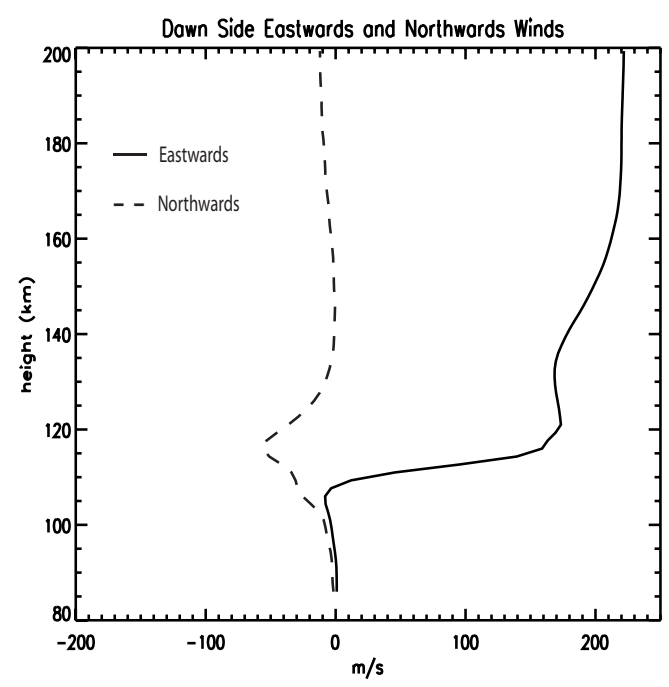

(b)

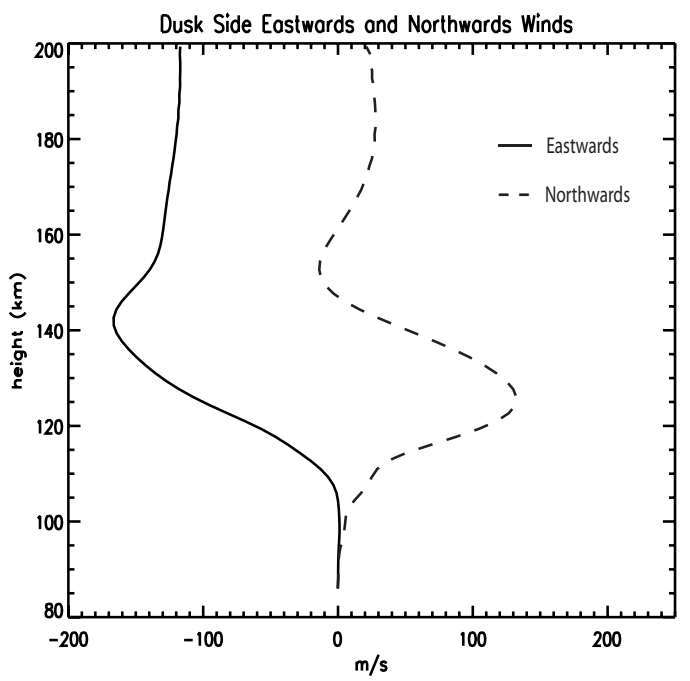

Fig. 2. Profiles of the simulated eastwards and northwards winds versus height, plotted at the center of the latitudinal and longitudinal domains, for equivalent conditions on the dawn and dusk sides (a) dawn side (b) dusk side.

launched into the recovery phase aurora at 04:20 UT. The rocket releases were oriented close to magnetic north, with an apogee $300 \mathrm{~km}$, and impact $350 \mathrm{~km}$ downrange. Upleg (southern trails) and downleg (northern trail) trimethyl aluminate (TMA) releases were carried by the rocket, as well as barium cannisters. TMA trails allowed neutral winds to be measured between $80-180 \mathrm{~km}$, barium releases measured neutral winds at $200 \mathrm{~km}$ and $280 \mathrm{~km}$, and barium drifts allowed electric fields to be estimated. The Chatanika incoherent scatter radar (3 km south of Poker Flat) was operating prior to, during and after the rocket flights, and scanned north along a magnetic meridian, giving plasma densities from 80 to $450 \mathrm{~km}$. Electric fields were estimated from ion drift measurements at 115 and $165 \mathrm{~km}$ altitudes. Defense Meteorological Satellite Program (DMSP) satellite photographs indicated the presence of a weak continuous visual aurora throughout the observing period. The geomagnetic activity was between around $\mathrm{Kp} 3.5$ and 5.5 throughout the observing period. Measurements during this period (Mikkelsen et al., 1981) suggest that there may have been mainly discrete aurora over the period of the observations, but from the point of view of the simulations, only precipitating energy flux matters, not whether it comes from discrete or diffuse aurora (we do not include the small spatial-scale ion density enhancements that comprise the discrete aurora and we also do not include the small spatial scale electric field structures associated with the discrete aurora).

\subsection{Simulations without background winds}

The Chatanika observations for 28 February 1978, were used to determine ion density and electric field structures over the observing period. To describe the changing auroral inputs over time, ion density and electric field structures were defined for two different time intervals leading up to and including the rocket launch at 04:20 UT, i.e. from 02:40 to $03: 30 \mathrm{UT}$, and from 03:30 to 04:20 UT. The ion density profiles, the latitudinal scaling factors for the ion densities, and the electric field latitudinal structures, are shown in Figs. 3a, b and c, respectively, for each interval, where the maximum electric field measured on the dusk side was around three times as large as that for the dawn side during the ARIA I campaign (see Mikkelsen et al., 1981; Brinkman et al., 1995). Simulations were performed using the specified ion density and electric field structures to provide auroral forcing inputs for the period of the observations, without any background winds. The results of the simulations for locations corresponding to the southern and northern trails are compared with the observations in Figs. 4a and b, and Figs. 5a and b, respectively.

General similarities are seen between the simulated and the observed structure for the zonal wind, although the westwards wind around $140 \mathrm{~km}$ is smaller than that observed, for both the northern and southern trails, and little structure is seen in the simulations below around $120 \mathrm{~km}$ altitude, where there is a large eastward shear around $115 \mathrm{~km}$. The simulated meridional wind structure differs significantly from the observations, especially for the southern trail. There is a small broad northwards wind maximum in the southern trail observations at $130 \mathrm{~km}$, of around 20 to $30 \mathrm{~m} / \mathrm{s}$, and in the northern trail observations there is a larger northwards maximum of around 90 to $100 \mathrm{~m} / \mathrm{s}$ between 130 and $150 \mathrm{~km}$ altitude. The simulations show a peak of more than $200 \mathrm{~m} / \mathrm{s}$ at $125 \mathrm{~km}$ altitude, which is in the same direction as that observed, but is 
(a)

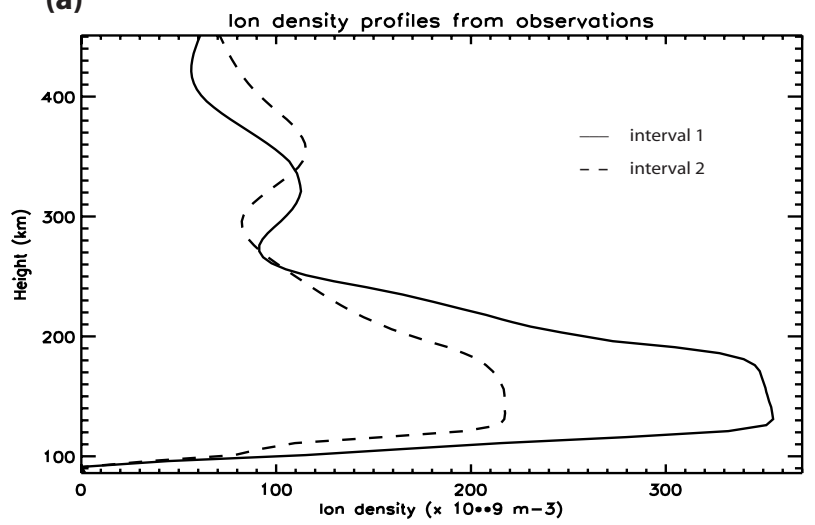

(b)

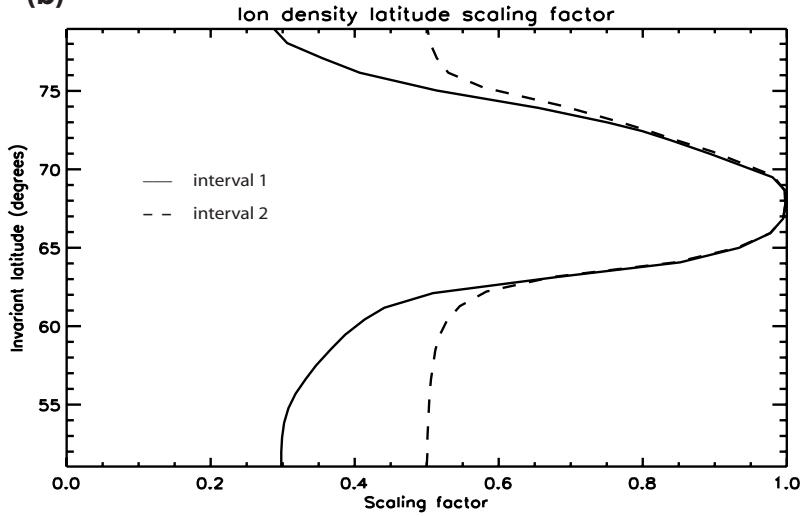

(c)

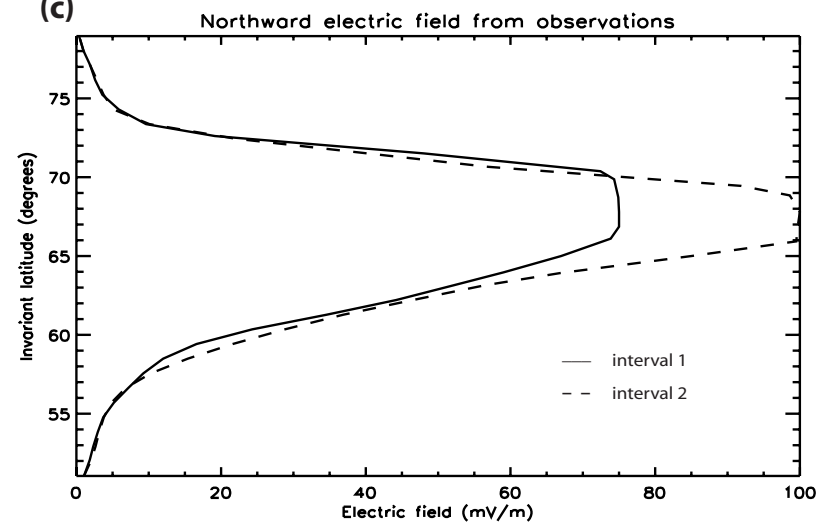

Fig. 3. Ion density and electic field structures used in the simulations, for the first and second intervals, inferred from the 28 February observations (a) ion density profile (b) latitude scaling factor for the ion density (c) northwards electric field.

\subsection{Effects of background winds and tides}

In Parish et al. (2003, 2006), we found that background winds and propagating tides have important effects on neutral winds within the dawn side of the aurora, and tend to improve the simulated wind structure in comparison with observations. We have introduced background winds and tides from the CTIP (Coupled Thermosphere Ionosphere Plasmasphere) model, appropriate for 28 February 1978. In this case, low geomagnetic activity was specified for the background wind field, to reduce any potential auroral forcing influence from within the background winds. It was found in Parish et al. $(2003,2006)$, that higher order semidiurnal tidal modes such as the $(2,5)$ and $(2,6)$ modes, which have relatively short vertical wavelengths, consistent with the short vertical scale lengths in the observations, produced the best agreement with the observed structures. These higher order semidiurnal tidal modes were included in the background winds, and in the examples shown here, the $(2,6)$ propagating tidal mode was included, with geopotential height amplitude $300 \mathrm{~m}$ and phase 05:00 LT, where propagating tides are forced at the lower boundary of the CTIP model at $80 \mathrm{~km}$ altitude. The results are shown in Figs. $4 \mathrm{c}$ and d, and $5 \mathrm{c}$ and $\mathrm{d}$ for the southern and northern trails, respectively.

When background winds are introduced, some vertical structure is seen below $120 \mathrm{~km}$ in the meridional and zonal winds in both the northern and southern trails. The zonal wind is still smaller than that observed, and the westwards peak around $140 \mathrm{~km}$ altitude is reduced slightly in magnitude, by around $50 \mathrm{~m} / \mathrm{s}$. There is a large maximum in the meridional wind around $125 \mathrm{~km}$ altitude, in the northwards direction, which is increased in magnitude by around $50 \mathrm{~m} / \mathrm{s}$, and magnitudes are also slightly increased above $160 \mathrm{~km}$ altitude, where they become slightly closer to those observed. With background winds and tides present, an eastwards peak appears around $105 \mathrm{~km}$ altitude, although this is smaller and lower in altitude than the observed peak around $115 \mathrm{~km}$. There is evidence of small maxima and minima in the meridional wind below $120 \mathrm{~km}$, in the same direction as the observed peaks, but these are much smaller than those measured. The addition of background winds with the observed tidal amplitude and phases for the $(2,6)$ tidal mode, therefore produces more vertical structure below $120 \mathrm{~km}$, which is consistent with that observed, but smaller in magnitude. The vertical structure above $120 \mathrm{~km}$ does not appear to be significantly improved by the addition of background winds.

\section{Sensitivity studies}

In order to determine the most important factors which influence the wind variations on the dusk side, and to investigate whether certain values of input parameters are able to produce a relatively close agreement with the observations, sensitivity studies have been performed, to determine the 
(a)

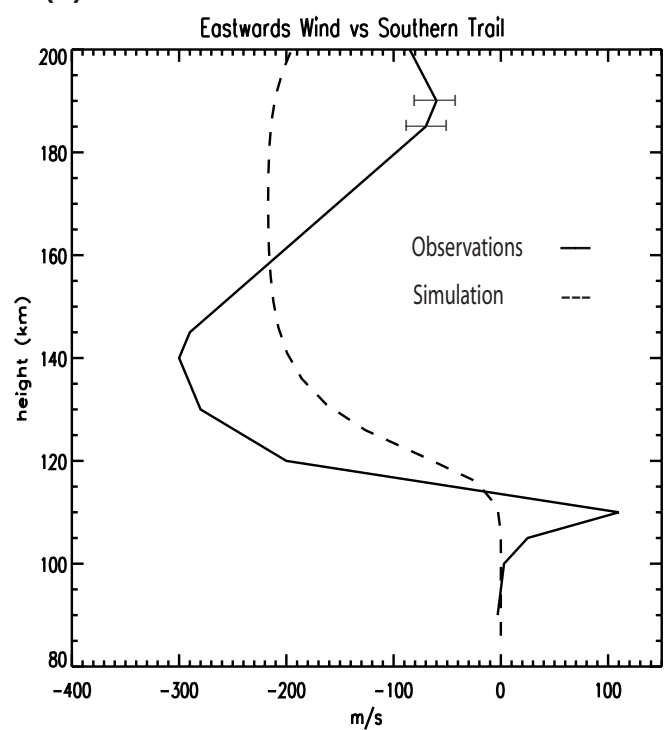

(c)

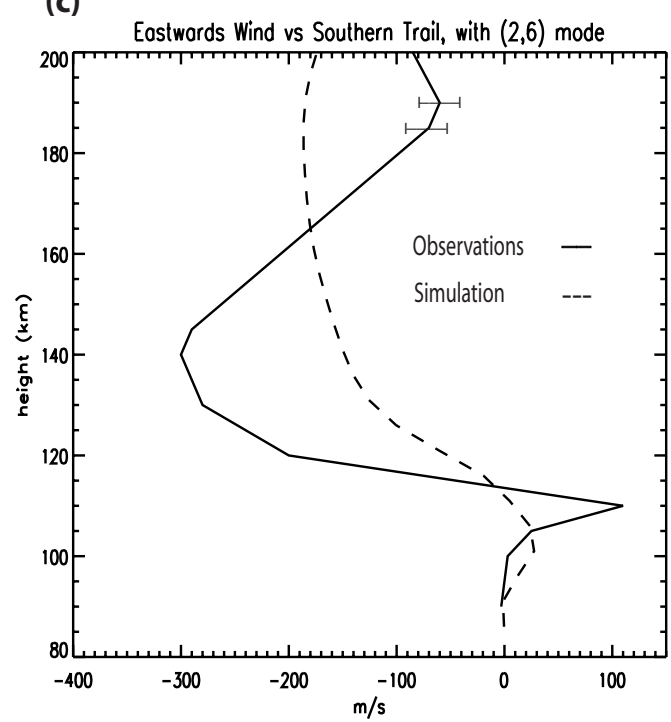

(b)

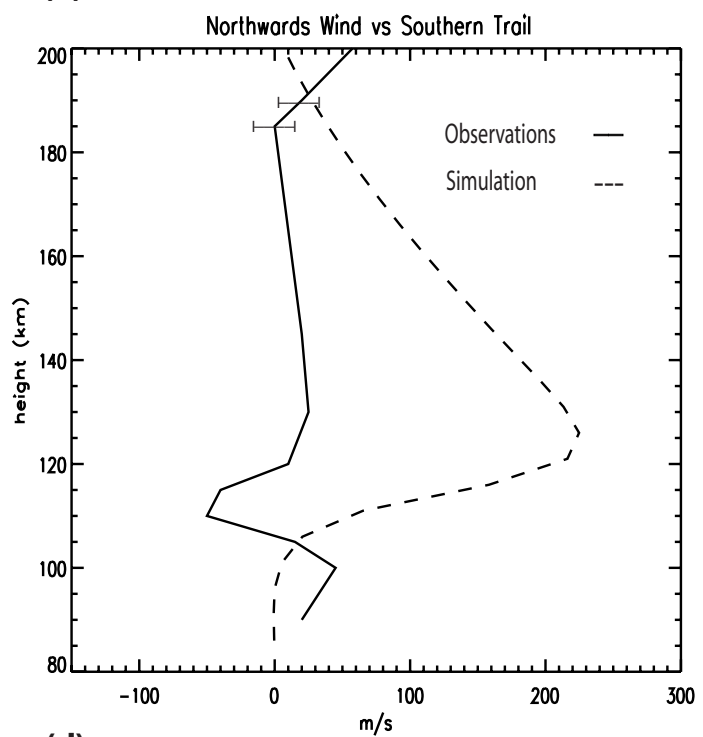

(d)

Northwords Wind vs Southern Trail, with $(2,6)$ mode

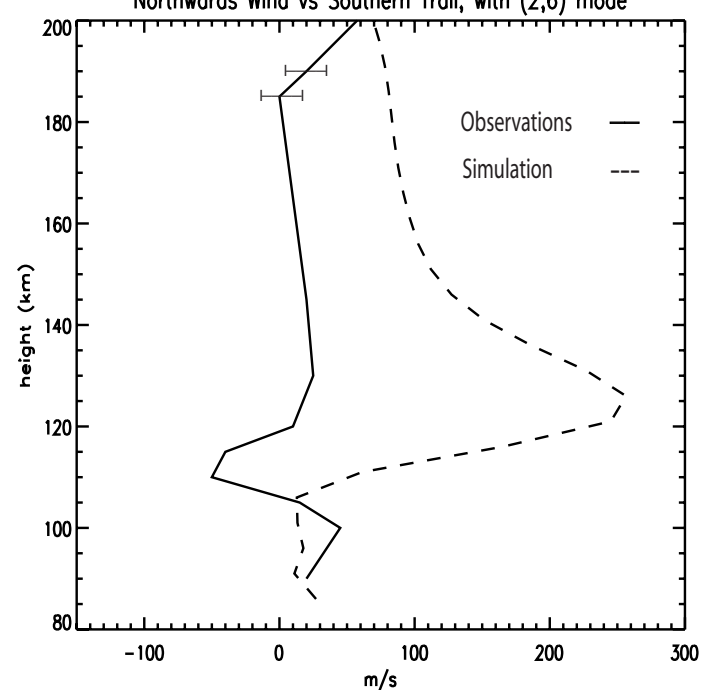

Fig. 4. Wind profiles simulated using ion densities and electric fields based on the 28 February dusk side campaign measurements. Results are compared with the southern trail winds observed during the same campaign. (a) and (b) response with no background winds (c) and (d) response with background winds including the $(2,6)$ mode, amplitude $300 \mathrm{~m}$, phase $5.0 \mathrm{~h}$.

effects of changes in the background winds, and changes in the electric field and ion density magnitudes and structures. The same $(2,6)$ tidal mode has been included in the background winds in these examples, with varying amplitude and phase. The electric field and ion density structures are based on the values measured during the 28 February campaign, with background ion densities provided by the Chiu empirical model.

\subsection{Variations in tidal amplitude and phase}

Since propagating tides are known to be variable (e.g. Pancheva et al., 2000; Beard et al., 1999; Canziani, 1994;
Phillips and Briggs, 1991) and tidal parameters at a given time and location are not well known unless measured directly, the amplitudes and phases of the propagating tides in the background winds were varied.

\subsubsection{Amplitude variation}

Figures $6 a$ and $b$, and $7 a$ and $b$, show the simulated winds produced with auroral forcing parameters based on the observations, for the southern and northern trails, respectively, with background winds including the $(2,6)$ tidal mode. The phase of the $(2,6)$ mode has been kept constant at 05:00 LT and the amplitude of the $(2,6)$ tidal mode has been varied 
(a)

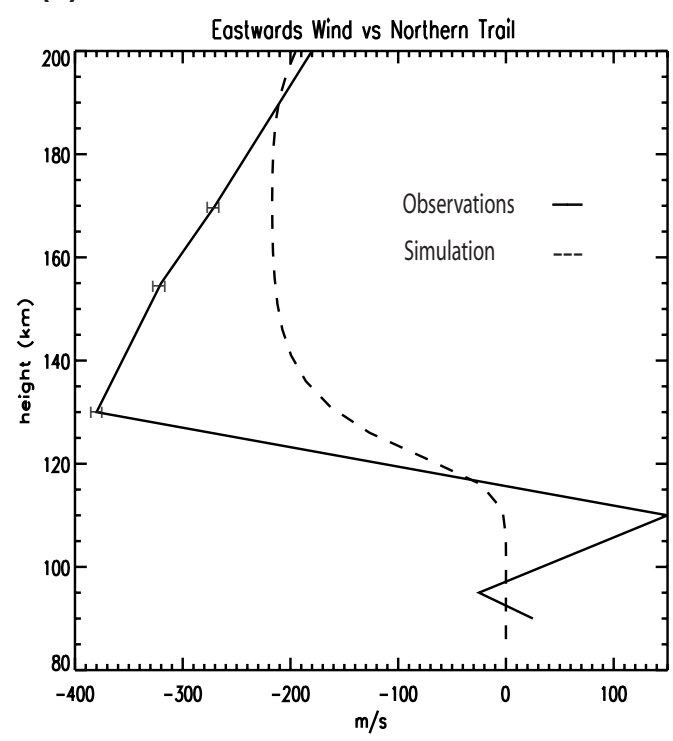

(c)

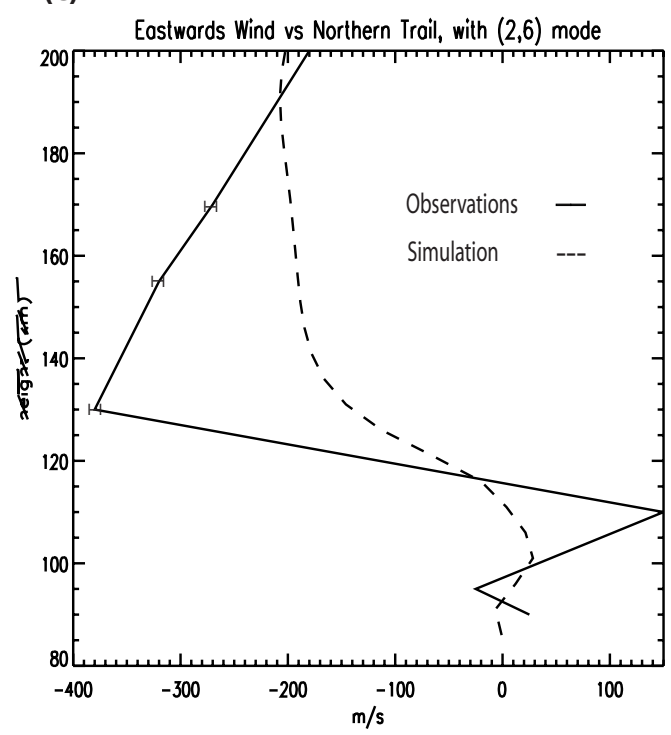

(b)

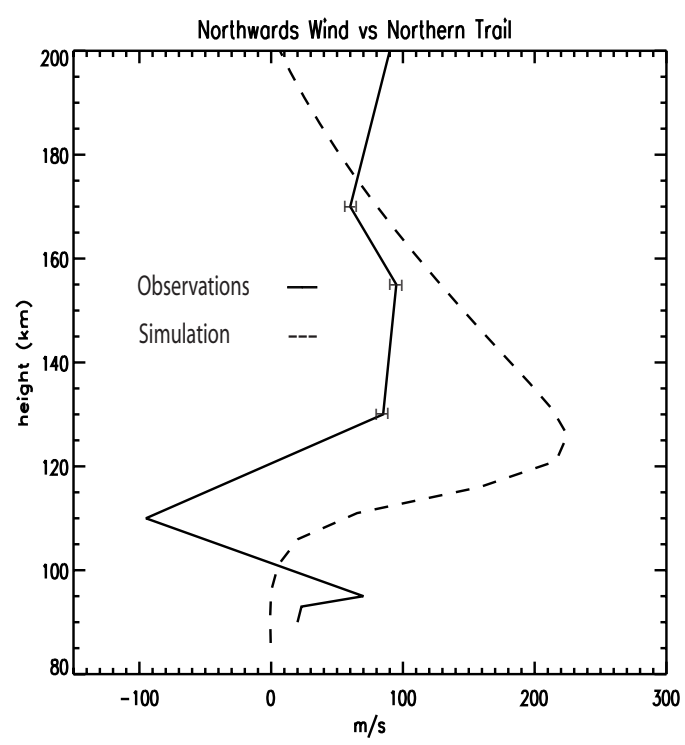

(d)

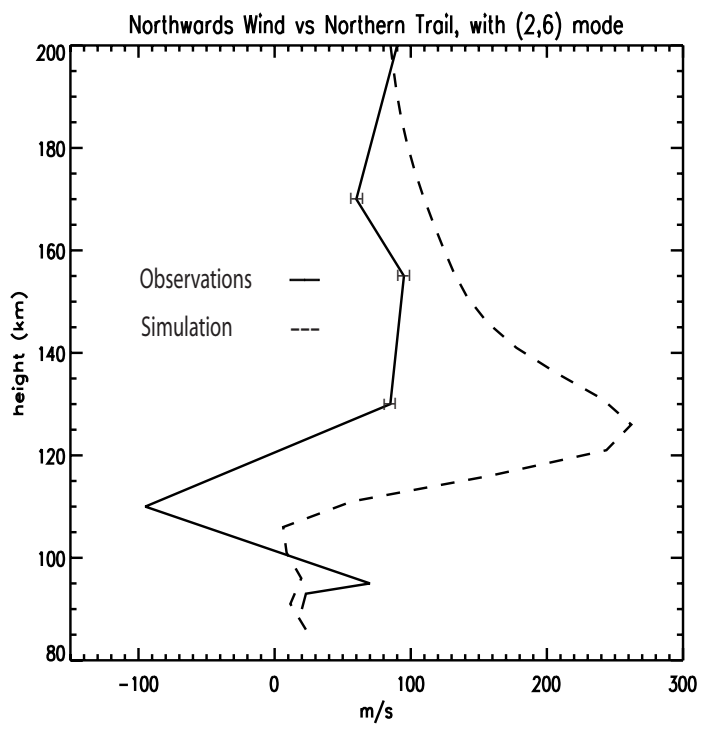

Fig. 5. As Fig. 4, but for northern trail observations.

between $100 \mathrm{~m}$ and $400 \mathrm{~m}$ geopotential height, where the range of tidal amplitudes is consistent with recent measurements (e.g. Hecht et al., 1998; Karpov, 1996; Dao et al., 1995), and with values found to produced reasonable agreement with observations on the dawn side (Parish et al., 2003, 2006). The simulated winds are compared with the measurements. Changing the amplitude of the $(2,6)$ model has a relatively small effect on the zonal wind magnitude, with increases of up to around 30 to $40 \mathrm{~m} / \mathrm{s}$, in the westwards direction above $160 \mathrm{~km}$, and slight decreases around $140 \mathrm{~km}$, as the amplitude of the tidal variation is increased. The northwards wind tends to decrease at all heights, as the tidal amplitude is increased, up to around $40 \mathrm{~m} / \mathrm{s}$. The altitudes of all the wind peaks remain approximately the same. The magnitudes of vertical variations below $120 \mathrm{~km}$ are not significantly affected in the case of the zonal wind, and produce changes around 20 to $30 \mathrm{~m} / \mathrm{s}$ in the meridional wind, but the strength of the observed shears around $115 \mathrm{~km}$ in both the meridional wind and zonal wind are not reproduced. The structures of the simulated meridional and zonal winds therefore do not appear to become significantly closer to those observed if the amplitude of the $(2,6)$ tidal mode is varied in the simulations. 
(a)

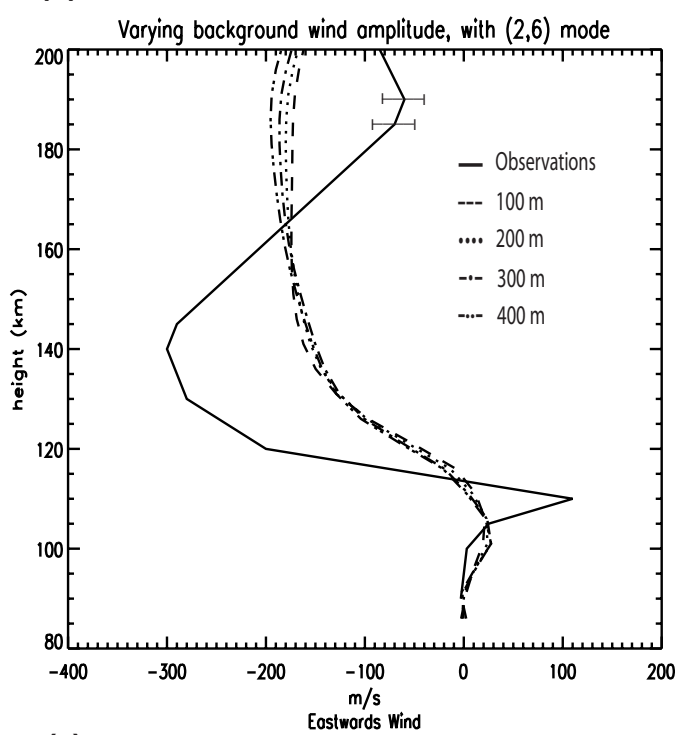

(c)

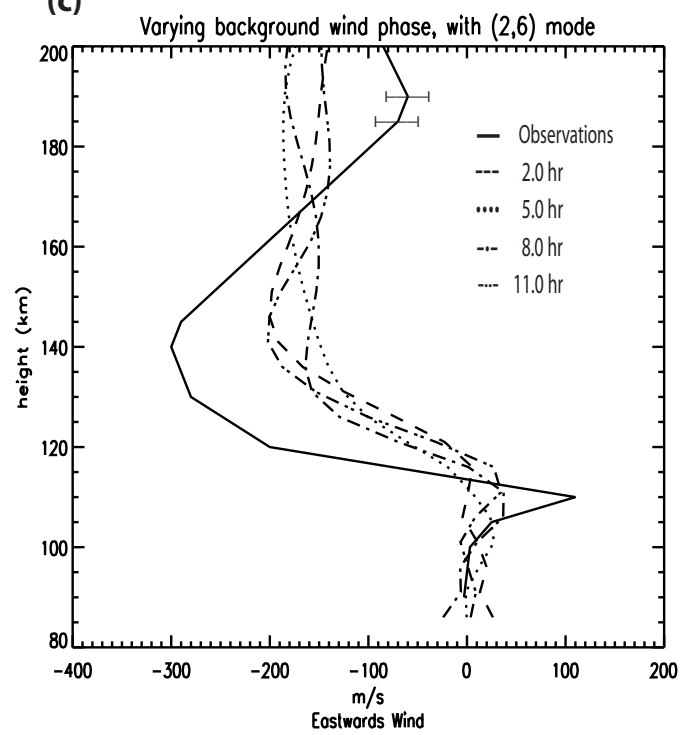

(b)

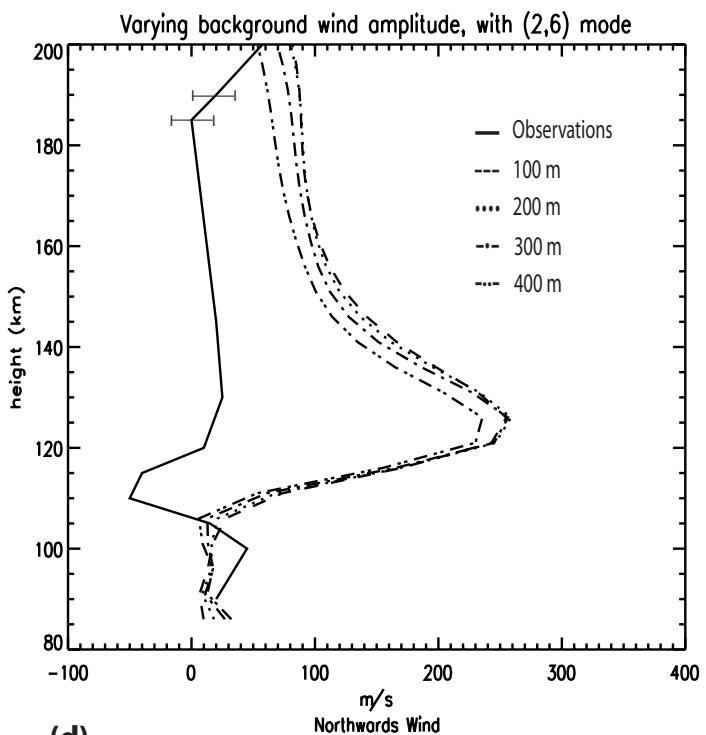

(d)

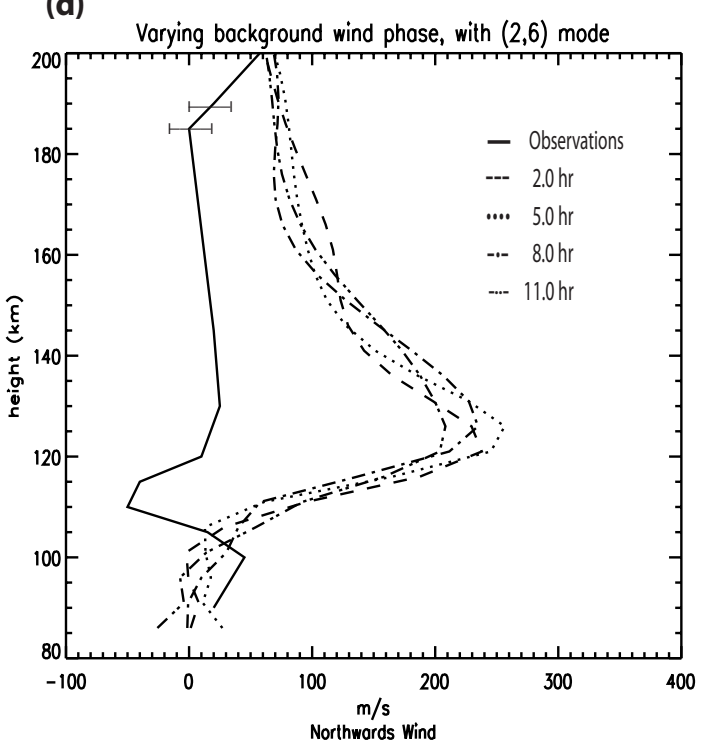

Fig. 6. (a) and (b) response of the neutral winds to changes in the amplitude of the $(2,6)$ tidal mode in the background winds, (c) and (d) response of the neutral winds to changes in the phase of the $(2,6)$ tidal mode in the background winds. Results are compared with the southern trail 28 February dusk side observations.

\subsubsection{Phase variation}

Figures $6 \mathrm{c}$ and d, and $7 \mathrm{c}$ and d, show the effects of changing the phase of the the $(2,6)$ tidal mode within the background winds, whilst keeping the tidal amplitude constant, at $300 \mathrm{~m}$, using auroral forcing parameters based on observations, as the phase is varied from 02:00 to 11:00 LT, in steps of $3.0 \mathrm{~h}$. The simulated peaks in the northwards and westwards winds show differences in altitude of 10 to $15 \mathrm{~km}$, as well as changes in magnitude of up to 50 to $60 \mathrm{~m} / \mathrm{s}$, as the phase is modified, and a clear westwards maximum close to $140 \mathrm{~km}$ appears around the same height as that observed, for some values of tidal phase. Whilst there are significant changes in the altitudes and magnitudes of the major westwards and northwards peaks, the simulated zonal peak around $140 \mathrm{~km}$ is still too small and the meridional wind peak around $125 \mathrm{~km}$ is still too large, in comparison with observations. The altitudes and directions of the wind maxima below $120 \mathrm{~km}$ change by up to around $40 \mathrm{~m} / \mathrm{s}$ with changing tidal phase, but the strong eastwards and southwards shears observed around $110 \mathrm{~km}$ are not well reproduced for any phase. 
(a)

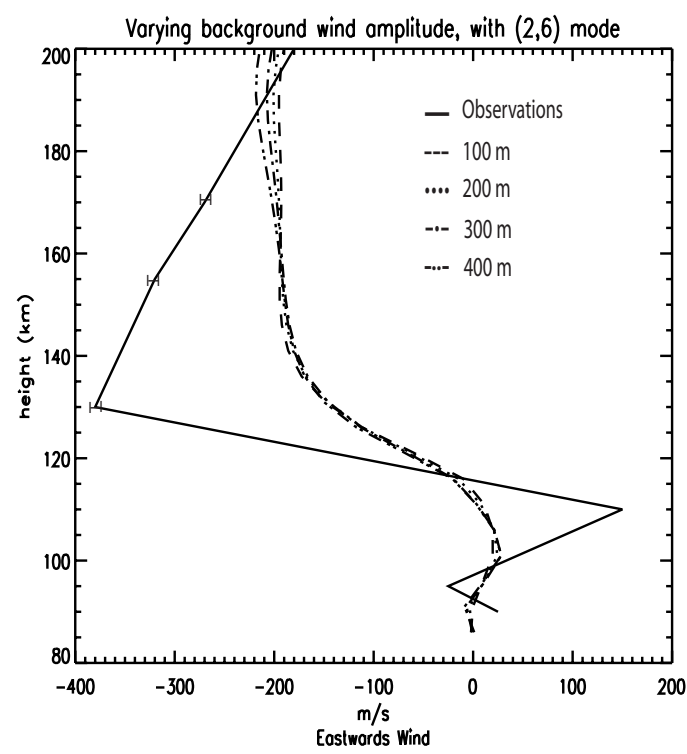

(c)

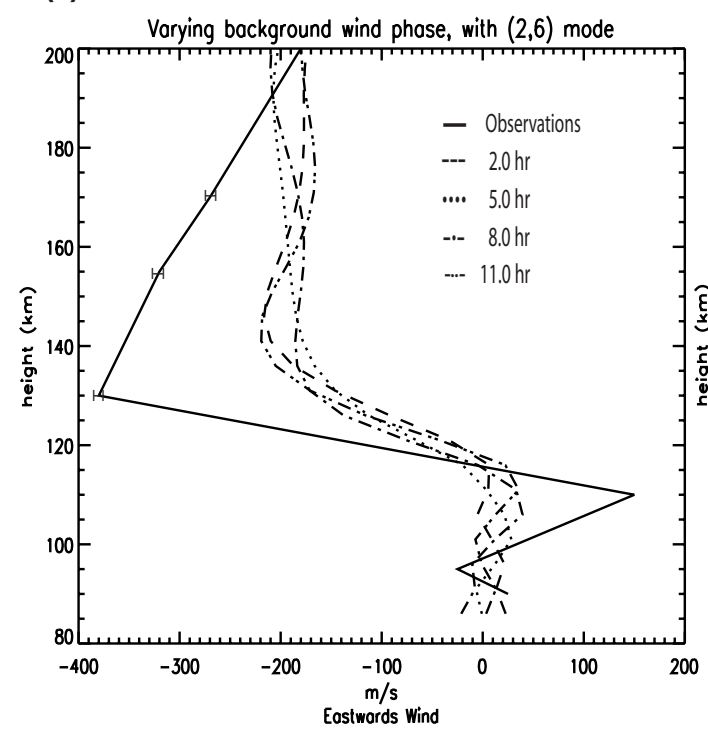

(b)

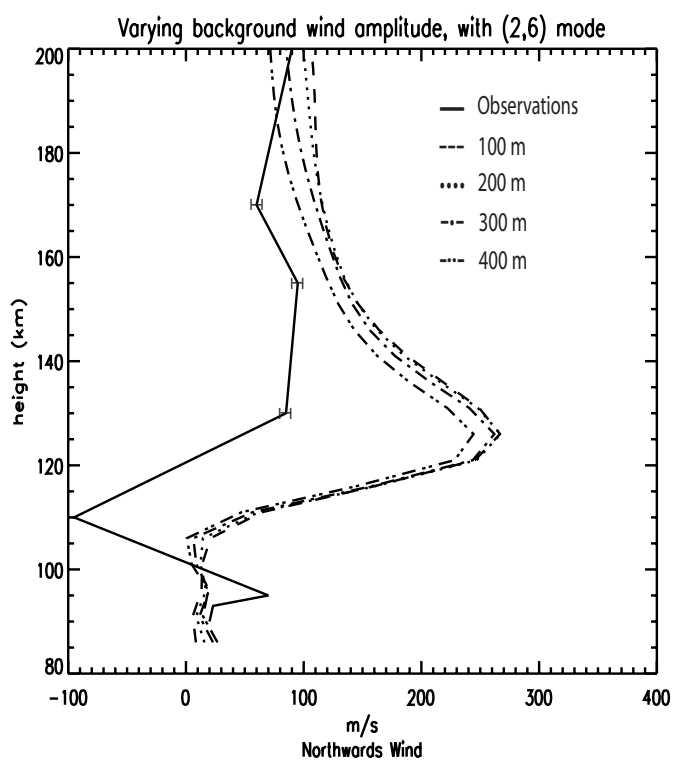

(d)

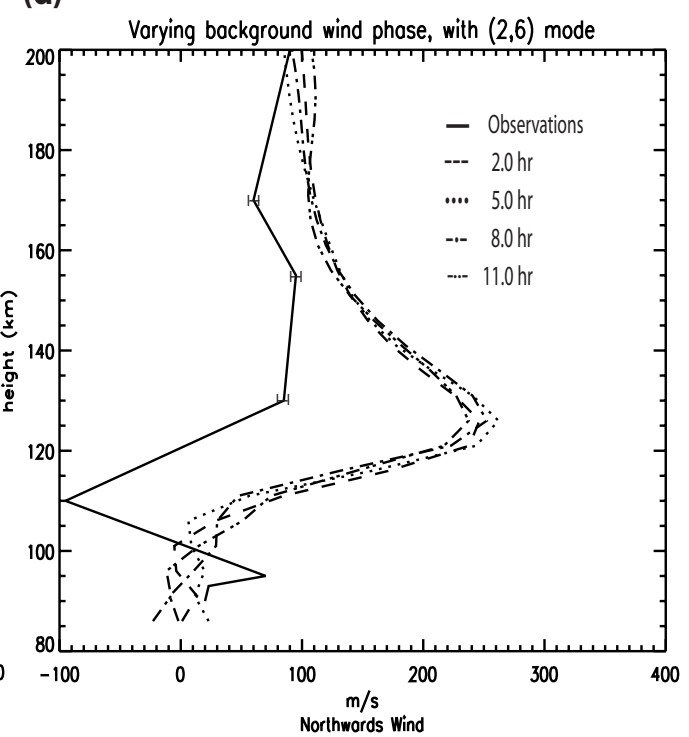

Fig. 7. As Fig. 6, but for the northern trail 28 February dusk side observations.

\subsection{Effects of changes in electric field and ion density}

The effects of changing the electric field and ion density magnitudes and structures with background winds present, were also investigated, In these examples the background wind included the $(2,6)$ tidal mode, with amplitude $300 \mathrm{~m}$ and phase $5.0 \mathrm{~h}$.

\subsubsection{Electric field variations}

The effects of changing the magnitude of the electric field whilst keeping the original ion density the same in the presence of background winds and tides, are shown in Figs. 8a and $b$, and $9 \mathrm{a}$ and $\mathrm{b}$, for the southern and northern trails respectively, where the original electric field has been multiplied by $0.5,1.0$, and 2.0 , respectively. As the electric field is increased, changes in the wind structure are seen above around $115 \mathrm{~km}$ for the zonal wind and around $100 \mathrm{~km}$ for the meridional wind. For the zonal wind, the westwards magnitude is significantly increased by around 50 to $100 \mathrm{~m} / \mathrm{s}$ at $140 \mathrm{~km}$ altitude as the electric field is increased, and is increased further at higher altitudes, where zonal wind magnitudes are overestimated. Zonal wind magnitudes are close to those observed around $150 \mathrm{~km}$ altitude, when the electric field is doubled, although there is no clear wind maximum 
(a)

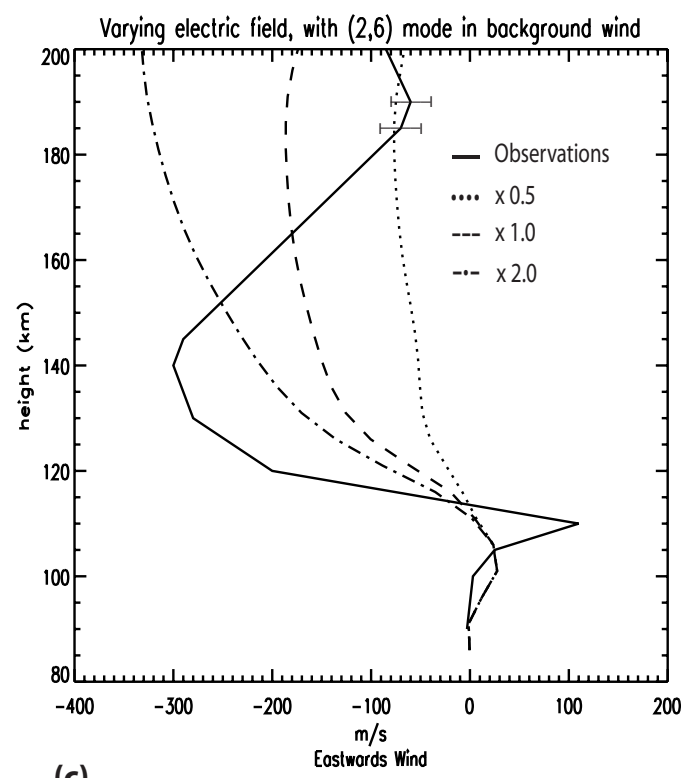

(c)

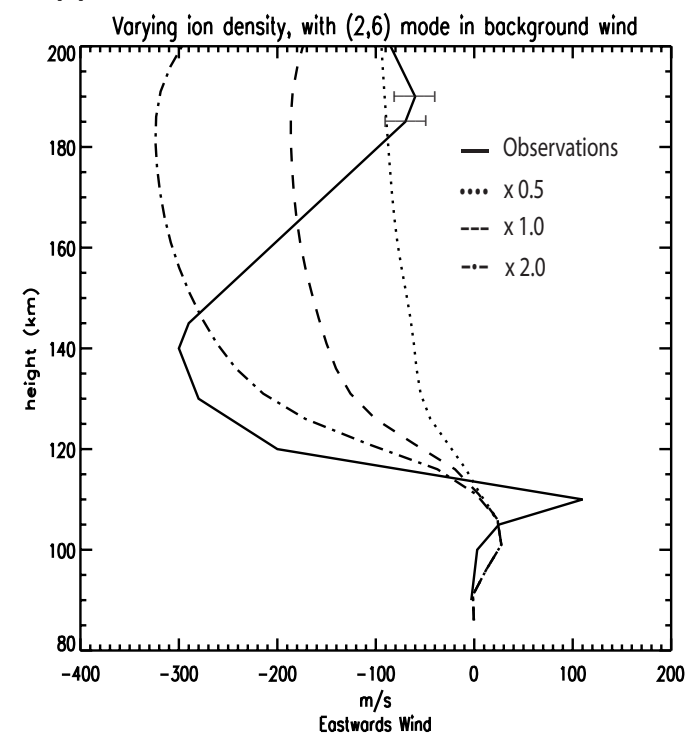

(b)

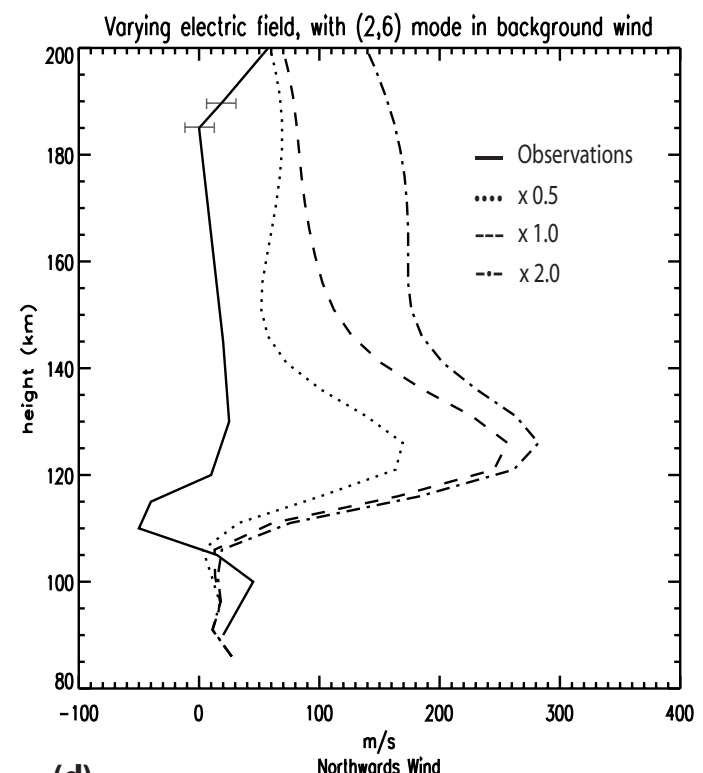

(d)

Northwords Wind

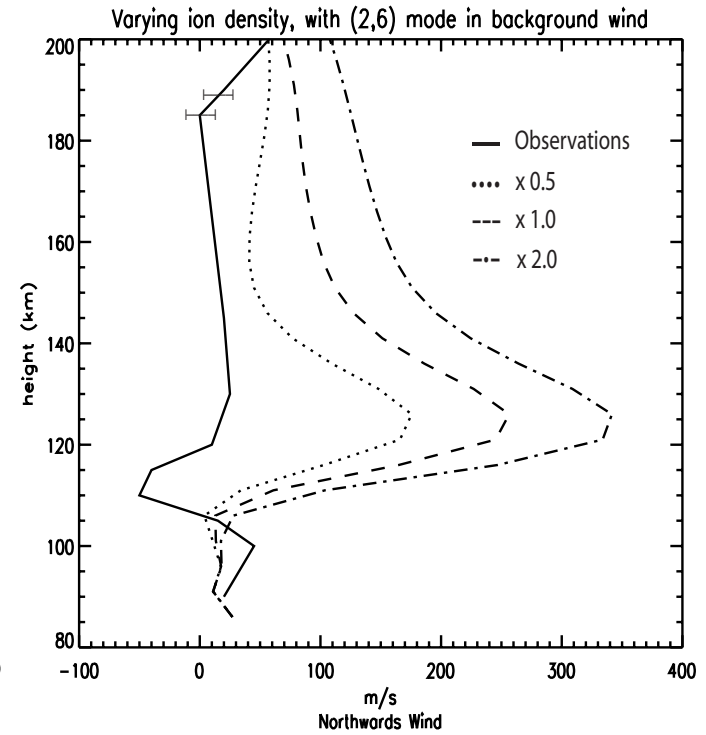

Fig. 8. (a) and (b) response of the neutral winds to varying electric field magnitude, with the $(2,6)$ tidal mode in the background winds, (c) and (d) response of the neutral winds to varying ion density enhancement, with the $(2,6)$ tidal mode in the background winds. The southern trail 28 February observations are included for comparison.

around 130 to $140 \mathrm{~km}$, comparable to that found in the observations. For the meridional wind, the northwards maximum around 125 to $130 \mathrm{~km}$ altitude is significantly increased by 50 to $100 \mathrm{~m} / \mathrm{s}$ as the electric field magnitude is increased. The small eastwards maximum around $105 \mathrm{~km}$ altitude is not noticeably affected by changes in the electric field, and the structure around $105 \mathrm{~km}$ in the meridional wind is changed by only 10 to $20 \mathrm{~m} / \mathrm{s}$ as the electric field is modified, and the strong shears observed around $110 \mathrm{~km}$ are not simulated for an increased electric field.

\subsubsection{Ion density variations}

Figures $8 \mathrm{c}$ and $\mathrm{d}$, and $9 \mathrm{c}$ and $\mathrm{d}$, show the effects of changing the magnitude of the ion density enhancement, whilst keeping the original electric field based on the dusk measurements, and the background ion density, the same, where the ion density enhancement has been multiplied by $0.5,1.0$, and 2.0, respectively. The effects of increases in ion density are similar to the effects of increasing the electric field for the zonal wind, although the increase in the westwards maximum is 5 to $10 \%$ larger for the ion density, producing values 
(a)

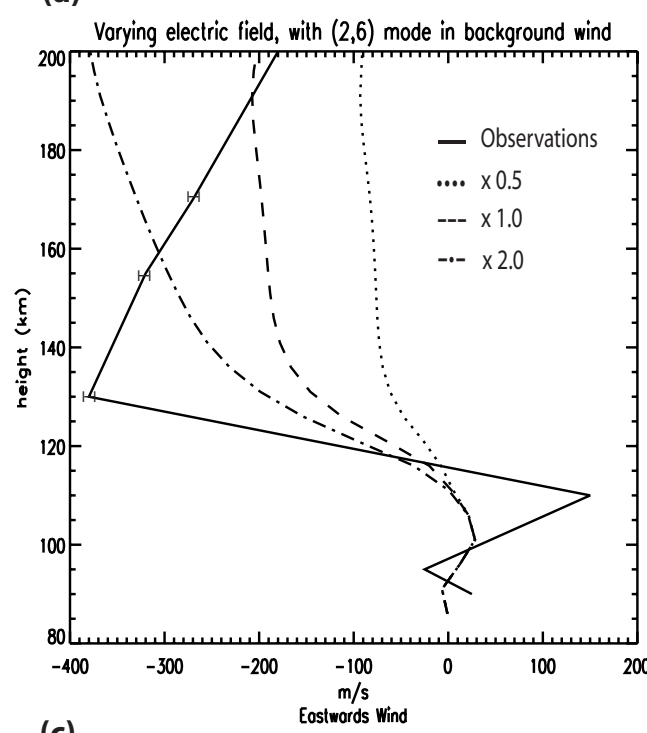

(c)

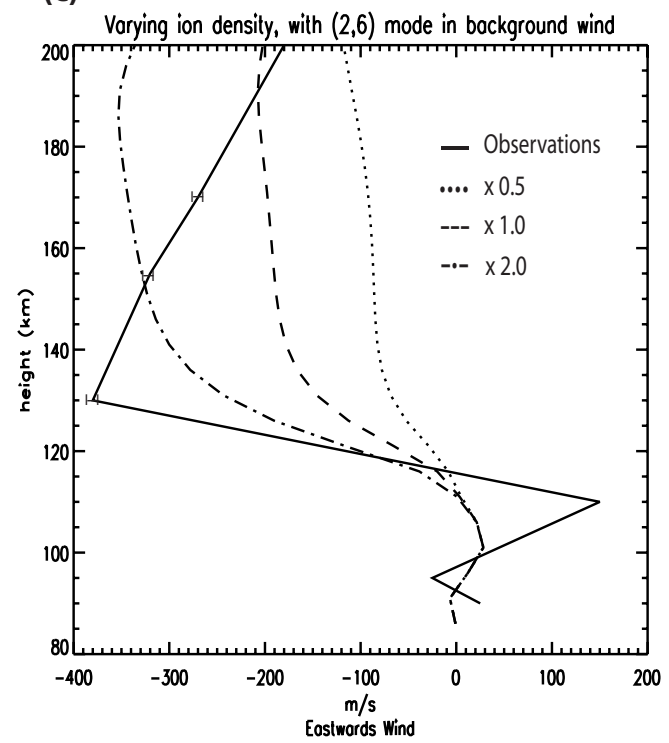

(b)

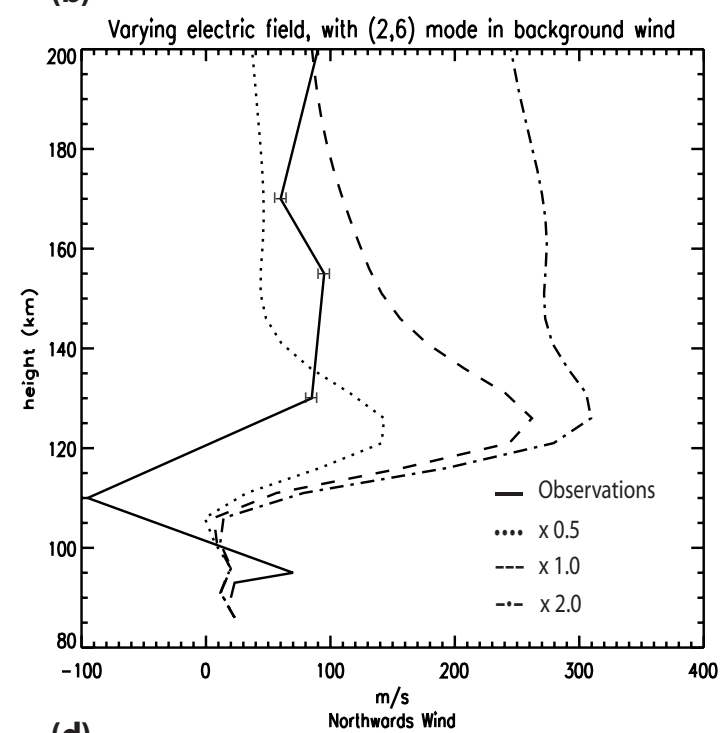

(d)

Vorying ion density, with $(2,6)$ mode in bockground wind

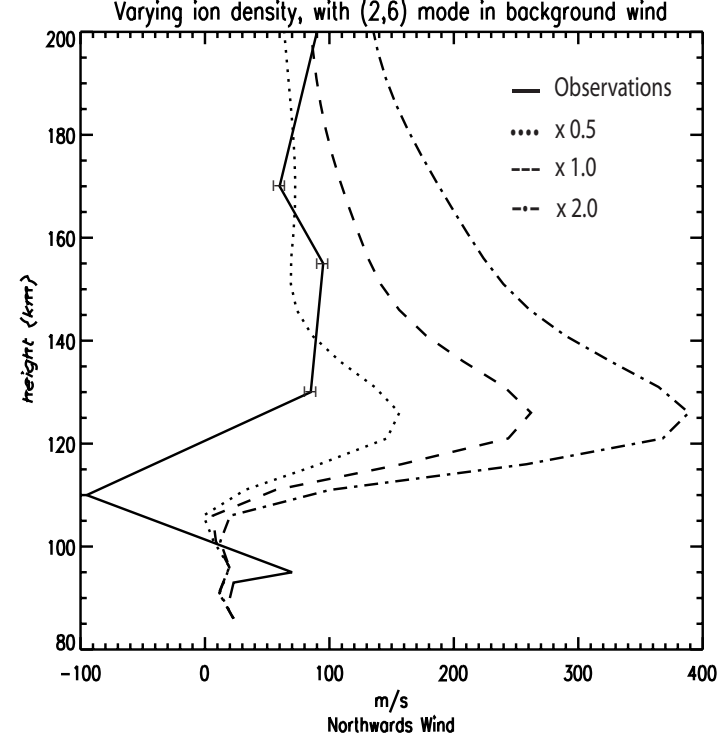

Fig. 9. As Fig. 8, but for the northern trail 28 February observations.

close to those observed near the magnitude peak around $140 \mathrm{~km}$, although there is no clear maximum in the westward wind around 130 to $140 \mathrm{~km}$ altitude. The northward peak around $125 \mathrm{~km}$ is increased 10 to $20 \%$ more for the ion density increases compared with the electric field increases, and the maximum around $125 \mathrm{~km}$ is still too large. Changes in the ion density have little effect on the zonal wind below $100 \mathrm{~km}$ altitude, and have only small effects around 20 to $30 \mathrm{~m} / \mathrm{s}$ on the meridional wind below $110 \mathrm{~km}$, and do not produce the observed strong maximum around $110 \mathrm{~km}$.

\section{Conclusions}

Observations from the dusk side rocket campaign of 28 February 1978 and from the dawn side ARIA campaigns, show that strong neutral winds are generated within both the premidnight and postmidnight sides of the aurora, where the measured winds on the dusk side are even stronger than those on the dawn side. When auroral forcing processes alone are introduced into the 3-D high resolution model simulations, with the same ion density and electric field magnitudes and structures on the dawn and dusk sides, differences are found in the generated wind structures on each side. Strong zonal wind velocities are produced on both the dawn and dusk sides, going in opposite directions on each side. The 
wind maxima occur at higher altitudes on the dusk side, the shears underneath the maxima are weaker on the dusk side, the maximum meridional wind is larger on the dusk side, and the wind structure appears to be more confined in latitude on the dusk side, where differences are related to the different balance of forces on the dawn and dusk sides, discussed above, the narrower region of heating and acceleration on the dusk side, and the 3-D circulation. However, the zonal winds around 130 to $140 \mathrm{~km}$ altitude do not appear to be larger on the dusk side than the dawn side, for comparable auroral forcing magnitudes.

When simulations are performed using ion density and electric field structures inferred from the 28 February dusk side measurements, without background winds, the simulated zonal wind shows some of the features of the measured winds, but the magnitude of the westwards maximum is smaller than that measured, and the simulated northwards wind peak around $125 \mathrm{~km}$ is larger than observed. Very little structure is seen below $120 \mathrm{~km}$ altitude. When background winds including the higher order semidiurnal $(2,6)$ propagating tidal mode are used in the simulations, with tidal forcing magnitudes consistent with recent observations, and with auroral forcing based on the 28 February dusk side measurements, more structure is seen below $120 \mathrm{~km}$, and small maxima and minima appear below $120 \mathrm{~km}$ in the same directions as those observed. The simulated structure above $120 \mathrm{~km}$ is also modified. However, the westwards wind magnitude around 130 to $140 \mathrm{~km}$ altitude is still significantly too small, and the northwards wind peak around $125 \mathrm{~km}$ is still too large, and the overall structure is not greatly improved in comparison with observations by the addition of background winds and tides. The assumption of low geomagnetic activity in the background wind field outside the auroral zone, to reduce any possible auroral influence from the background winds, could have effects on the simulated wind profiles, and the sensitivity to changes in activity levels in the background winds will be determined in future simulations. Sensitivity studies show that varying the amplitude of the tidal variations in the background winds affects the magnitudes of the peaks, and varying the tidal phase alters the magnitudes and heights of the peaks at all altitudes, but does not significantly improve the general height structure of the winds above $120 \mathrm{~km}$ in comparison with observations. The simulated response with background winds included, is found to be sensitive to the magnitudes of the electric field and ion density enhancement. Enhancing the electric field or the ion density can increase the magnitude of the large zonal wind peak around $140 \mathrm{~km}$ to values comparable with those observed, although in order to reproduce the observed strong zonal winds, values of electric field or ion density larger than those observed are needed. Increasing the electric field or ion density also tends to enhance the northwards peak around $125 \mathrm{~km}$, to values which are considerably larger than those observed. However, the neutral response may also be sensitive to the longer time history of the auroral forcing (Mikkelsen and Larsen,
1993), and the effects of the longer term history may also be taken into account in future simulations, where observations are available.

The structure below $120 \mathrm{~km}$ appears to be related to background winds and tides rather than auroral forcing, as was found to be the case on the dawn side (Parish et al., 2006). However, shears as large as those observed are not reproduced around $110 \mathrm{~km}$, for any values of tidal forcing parameters in the background wind field. This suggests that there may be other processes involved in producing the neutral variations that are not currently simulated. As suggested for simulations on the dawn side, these might involve unmodeled sub grid scale structures in the background winds, or might be related to the presence of other kinds of waves e.g. gravity waves, non-migrating semidiurnal tides (Portnyagin et al., 1998; Forbes et al., 1995), or waves generated by nonlinear interactions between existing waves (e.g. Pancheva et al., 2004; Isler and Fritts, 1996; Forbes et al., 1991), which are not currently included in simulations.

Acknowledgements. This work was supported by grant ATM0242292 from the National Science Foundation.

Topical Editor U.-P. Hoppe thanks I. McCrea and D. Winningham for their help in evaluating this paper.

\section{References}

Anderson, P. C., Christensen, A. B., Sharber, J. R., et al.: The ARIA I Rocket Campaign, J. Geophys. Res., 100, 17 265-17 284, 1995.

Bailey, G. J., Balan, N., and Su, Y. Z.: The Sheffield University plasmasphere ionosphere model - a review, J. Atmos. Solar-Terr. Phys., 59, 1541-1552, 1997.

Beard, A. G., Mitchell, N. J., Williams, P. J. S., and Kunitake, M.: Non-linear interactions between tides and planetary waves resulting in periodic tidal variability, J. Atmos. Solar-Terr. Phys., 61, 363-376, 1999.

Brinkman, D. G., Walterscheid, R. L., Lyons, L. R., et al.: E-region Neutral Winds in the Postmidnight Diffuse Aurora During the Atmospheric Response in Aurora I Rocket Campaign, J. Geophys. Res., 100, 17 309-17320, 1995.

Canziani, P. O.: On Tidal Variability and the Existence of Planetary Wave-Like Oscillations in the Upper Thermosphere. 1. Observations of Tidal Variability, J. Atmos. Terr. Phys., 56, 901-912, 1994.

Chiu, Y. T.: An improved Phenomenological Model of Ionospheric Density, J. Atmos. Terr. Phys., 37, 1563-1570, 1975.

Christensen, A. B., Hecht, J. H., and Walterscheid, R. L.: Depletion of Oxygen in Aurora: Evidence for a Local Mechanism, J. Geophys. Res., 102, 22 273-22 278, 1997.

Dao, P. D., Farley, R., Tao, X., and Gardner, C. S.: Lidar Observations of the Temperature Profile Between 25 and $103 \mathrm{~km}-$ Evidence of Strong Tidal Perturbation, Geophys. Res. Lett., 22, 2825-2828, 1995.

Forbes, J. M., Jun, G., and Miyahara, S.: On the interactions between Gravity-Waves and the Diurnal Propagating Tide, Plan. Space Sci., 39, 1249-1257, 1991.

Forbes, J. M., Makarov, N. A., and Portnyagin, Y. I.: First results from the meteor radar at south pole: A large 12-hour oscillation 
with zonal wavenumber one Geophys. Res. Lett., 22, 3247-3250, 1995.

Fuller-Rowell, T. J.: A Two-Dimensional, High Resolution, NestedGrid Model of the Thermosphere 1. Neutral Response to an Electric Field "Spike”, J. Geophys. Res., 89, 2971-2990, 1984.

Fuller-Rowell, T. J.: A Two-Dimensional, High Resolution, NestedGrid Model of the Thermosphere 2. Response of the Thermosphere to Narrow and Broad Electrodynamic Features, J. Geophys. Res., 90, 6567-6586, 1985.

Fuller-Rowell, T. J., Rees, D., Quegan, S., Moffett, R. J., and Bailey, G. J.: Interactions with Neutral Thermospheric Composition and the Polar Ionosphere Using a Coupled Ionosphere-Thermosphere Model, J. Geophys. Res., 92, 7744-7748, 1987.

Hecht, J. H., Walterscheid, R. L., Roble, R. G., et al.: A comparison of atmospheric tides inferred from observations at the mesopause during ALOHA-93 with the model predictions of the TIME-GCM, J. Geophys. Res., 103, 6307-6321, 1998.

Isler, J. R. and Fritts, D.: Gravity wave variability and interaction with lower-frequency motions in the mesosphere and lower thermosphere over Hawaii, J. Atmos. Sci., 53, 37-48, 1996.

Karpov, I. V.: Mode Structure of Tides in the Lower Thermosphere by Wind Measurements on UARS, Geomag. Aeron., 36, 202206, 1996.

Larsen, M. F., Mikkelsen, I. S., Meriwether, J. W., et al.: Simultaneous Observations of Neutral Winds and Electric Fields at Spaced Locations in the Dawn Auroral Oval, J. Geophys. Res., 94, 17 235-17 243, 1989.

Larsen, M. F., Marshall, T. R., Mikkelsen, I. S., et al.: Atmospheric Response in Aurora Experiment: Observations of E and F Region Neutral Winds in a Region of Postmidnight Diffuse Aurora, J. Geophys. Res., 100, 17 299-17 308, 1995.

Larsen, M. F., Christensen, A. B., and Odom, C. D.: Observations of Unstable Atmospheric Shear Layers in the Lower E-region in the Postmidnight Auroral Oval, Geophys. Res. Lett., 24, 19151918, 1997.

Lyons, L. R. and Walterscheid, R. L.: Generation of Auroral Omega Bands by Shear Instability of the Neutral Winds, J. Geophys. Res., 90, 12 321-12 329, 1985.

Lyons, L. R. and Fennell, J. F.: Characteristics of Auroral Electron Precipitation on the Morningside, J. Geophys. Res., 91, $11225-$ $11234,1986$.

Mikkelsen, I. S., Jorgensen, T. S., Kelley, M. C., et al.: Neutral Winds and Electric Fields in the Dusk Auroral Oval, 1. Measurements, J. Geophys. Res., 86, 1513-1524, 1981.

Mikkelsen, I. S. and Larsen, M. F.: Comparisons of Spectral Thermospheric General Circulation Model Simulations and E and F region Chemical Release Wind Observations, J. Geophys. Res., 98, 3693-3709, 1993.

Pancheva, D., Mukhtarov, P., Mitchell, N. J., Beard, A. G., and Muller, H. G.: A comparative study of winds and tidal variability in the mesosphere/lower-thermosphere region over Bulgaria and the UK, Ann. Geophys., 18, 1304-1315, 2000,

http://www.ann-geophys.net/18/1304/2000/.
Pancheva, D., Mitchell, N. J., Manson, A. H., et al.: Variability of the quasi-2-day wave observed in the MLT region during the PSMOS campaign of June-August 1999, J. Atmos. and SolarTerr. Phys., 66, 539-565, 2004.

Parish, H. F., Gladstone, G. R., and Chakrabarti, S.: Interpretation of Satellite Airglow Observations During the March 22, 1979, Magnetic Storm, Using the Coupled Ionosphere-Thermosphere Model Developed at University College London, J. Geophys. Res., 99, 6155-6166, 1994.

Parish, H. F, Robinson, T. R., Stocker, A. J., and Jones, T. B.: Evidence of Gravity Wave Structures in CUTLASS Radar Measurements, Adv. Space Res., 20, 1257-1260, 1997.

Parish, H. F., Walterscheid, R. L., Jones, P. W., and Lyons, L. R.: Simulations of the Thermospheric Response to the Diffuse Aurora Using a Three-Dimensional High Resolution Model, J. Geophys. Res., 108(A4), 1140, doi:10.1029/2002JA009610, 2003.

Parish, H. F. and Lyons, L. R.: Sensitivity studies of the E region neutral response to the postmidnight diffuse aurora, Ann. Geophys., 24, 1551-1565, 2006, http://www.ann-geophys.net/24/1551/2006/.

Phillips, A. and Briggs, B. H.: The day-to-day Variability of Upper Atomsphere Tidal Winds and Dynamo Currents, J. Atmos. Terr. Phys., 53, 39-47, 1991.

Portnyagin, Y. I., Forbes, J. M., Makarov, N. A., Merzlyakov, E. G., and Palo, S.: The summertime 12-h wind oscillation with zonal wavenumber $\mathrm{s}=1$ in the lower thermosphere over the South Pole, Ann. Geophys., 16, 828-837, 1998, http://www.ann-geophys.net/16/828/1998/.

Richmond, A. D. and Matsushita, S.: Thermospheric Response to a Magnetic Substorm, J. Geophys. Res., 80, 2839-2850, 1975.

St.-Maurice, J.-P. and Schunk, R. W.: Ion-Neutral Momentum Coupling Near Discrete High-Latitude Ionospheric Features, J. Geophys. Res., 80, 11 299-11 321, 1981.

Walterscheid, R. L. and Lyons, L. R.: The Neutral E-region Zonal WInds During Intense Postmidnight Diffuse Aurora: Response to Observed Particle Fluxes, J. Geophys. Res., 94, 3703-3712, 1989.

Walterscheid, R. L., Lyons, L. R., and Taylor, K. E.: The Perturbed Neutral Circulation in the Vicinity of a Symmetric Stable, J. Geophys. Res., 90, 12 235-12 248, 1985.

Weimer, D. R.: Models of High-Latitude Electric Potentials Derived with a Least Error Fit of Spherical Harmonic Coefficients, J. Geophys. Res., 100, 19595-19608, 1995.

Weimer, D. R.: A Flexible, IMF Dependent Model of High-Latitude Electric Potentials Having Space Weather Applications, Geophys. Res. Lett., 23, 2549-2552, 1996.

Weimer, D. R.: An improved model of ionospheric electric potentials including substorm perturbations and application to the Geospace Environment Modeling November 24, 1996, event, J. Geophys. Res., 106, 407, doi:2000JA000604, 2001. 